\title{
Intravenous methylprednisolone versus intravenous immunoglobulin in chronic inflammatory demyelinating polyradiculoneuropathy: a randomized trial
}

\author{
Kashyap PV ${ }^{1}$, Bhat $\mathrm{SJ}^{2}$ \\ ${ }^{1}$ Dr Priyanka V Kashyap, Assistant Professor Neurology, ${ }^{2}$ Dr Sunil Jee Bhat, Senior Resident, Medicine, both are \\ affiliated with Shri Guru Ram Rai Institute of Medical and Health Sciences and Shri Mahant Indiresh Hospital, \\ Dehradun, Uttrakhand, India.
}

Address for Correspondence: Dr Priyanka V Kashyap, A-60 MIG MDDA Colony, Dalanwala, Dehradun, Uttrakhand. Email: dr_pvinod@yahoo.co.in

\begin{abstract}
Introduction: Corticosteroids and Intravenous immunoglobulin (IVIg) are effective as initial treatment in patients with chronic inflammatory demyelinating polyradiculoneuropathy (CIDP), but their long-term use is less defined. We compared the efficacy and tolerability of 6-month therapy of intravenous methylprednisolone (IV MP) versus IVIg. Methods: This trial compared efficacy and tolerability of IVIg $(0 \cdot 5 \mathrm{~g} / \mathrm{kg}$ per day for 4 consecutive days $)$ and IV MP $(0 \cdot 5$ $\mathrm{g}$ in $250 \mathrm{ml}$ sodium chloride solution per day for 4 consecutive days) given every month for 6 months were assessed. After therapy discontinuation, patients were followed up for 6 months to assess relapses. Results: 40 patients (20 IV MP, 20 IVIg) completed the study. More patients stopped MP (12 [60\%] of 20) than IVIg (8 [40\%] of 20; relative risk 0.54, 95\% CI 0.34-0.87; $\mathrm{p}=0 \cdot 0085$ ). When adjusted for sex, age, disease duration, comorbidity, modified Rankin scale (mRS) at enrolment, and previous treatment with IVIg and steroids, the difference between the two groups remained significant (odds ratio 7.6, 95\% CI 1.7-33.8; $\mathrm{p}=0.0070$ ). Reasons for discontinuation were lack of efficacy (twelve in the IV MP group vs. 8 in the IVIg group), adverse events (one in the IV MP group), or voluntary withdrawal (2 in IV MP group). The proportion of patients with adverse events did not differ between IV MP group (14 [67\%] of 20) and IVIg group (11 [46\%] of 20; $\mathrm{p}=0.1606)$. After discontinuation, more patients on IVIg worsened and required further therapy (eight [38\%] of 20, p=0.0316). Conclusion: Treatment of CIDP with IVIg for 6 months was less frequently discontinued than with IV MP.
\end{abstract}

Keywords: Immunopathies, Polyneuropathy, Efficacy, Intolerance

\section{Introduction}

Chronic inflammatory demyelinating polyradiculoneuropathy (CIDP) is a chronic relapsing or progressive neuropathy $[1,2]$. CIDP is often disabling with over $50 \%$ of patients having temporary disability and about $10 \%$ eventually becoming persistently disabled or dying because of the disease [3].

Its prevalence ranges from 0.8 to 8.4 per 100000 people $[4,5]$. Data supporting an immune pathogenesis [6] have led to the use of immune therapies. Randomized trials and some uncontrolled studies on

Manuscript received $26^{\text {th }}$ May 2016

Reviewed: $8^{\text {th }}$ June 2016

Author Corrected: $24^{\text {th }}$ June 2016

Accepted for Publication $4^{\text {th }}$ July 2016
CIDP patients have shown the efficacy of corticosteroids, plasma exchange, and intravenous immunoglobulin (IVIg) [7-9]. Two randomized trials on a small population of patients showed a comparable short-term efficacy of IVIg and oral corticosteroids [10] and of IVIg and plasma exchange [11]. Little is known about the efficacy of these therapies over the long term. In a randomized trial, IVIg was more efficacious than placebo for 6 months and possibly up to 12 months $[12,13]$, whereas a similar remission rate was seen over 12 months with the use of either daily oral corticosteroids or pulsed high-dose dexamethasone [14]. The comparative efficacy and tolerance of IVIg or corticosteroids over this period remains unclear. We 
compared the efficacy and tolerability of 6-month therapy with intravenous methylprednisolone and IVIg in patients with CIDP.

\section{Methods}

It was a Double blind, Randomized trial. Patients with CIDP were enrolled from 2010- 2014. Eligible patients included age at least 18 years, had definite typical CIDP according to European federal of neurological society criteria [15] and had disability scoring 2 or more on either the overall neuropathy limitation scale (ONLS) [16].

Patients excluded were pregnant females, having atypical CIDP [15], multifocal motor neuropathy [17], underlying diabetes, and $\operatorname{IgM}$ monoclonal gammopathy, concurrent medical disorders preventing treatment or assessment. On trial entry, patient should not have had known contraindication to steroids like heart failure, cataract, psychosis, uncontrolled hypertension, gastric ulcer or allergy to IVIg, IgA deficiency, renal insufficiency. Informed consent was taken from all patients and the study was approved by the ethical committee. Randomization was done with a computer generated 1:1 randomization scheme.

Patients were randomly assigned to receive in 1:1 proportion either IVIg at doses $0.5 \mathrm{~g} / \mathrm{kg}$ x 4 consecutive days and IV steroids $0.5 \mathrm{gm}$ in $250 \mathrm{ml}$ sodium chloride solution for 4 consecutive days.

Each patient treated for 28 days (within 3 days) for 6 months. After 6 months, therapy was discontinued and patients followed up for further 6 months for deterioration (worsening by at least one point in the ONLS). During the 4 days of therapy, patients received either omeprazole or another gastro protective agent.

Patients were screened within 30 days before enrollment with medical assessment including measurement of blood pressure and body weight, electrocardiography, chest X-ray, complete neurological assessment, nerve conduction study on minimum 4 motor and 3 sensory nerves for demyelination, routine blood investigations and intraocular pressure. Severity of neuropathy was graded with MRS and ONLS.

After enrollment, patients were assessed before (month 0 ) and 15 days after the $1^{\text {st }}$ therapy then every month before each therapy course and 1 month after last therapy (month 6).
Patients were subsequently assessed every 2 months until 12 months. Each periodic assessment included several investigations. General assessment includes enquiry about side effects. Neurologic assessment include ONLS score (range 0-12, healthy to unable to perform any purposeful movements with arms and legs (0-5 in the arms and 0-7 in the legs) [16-19], MRS score (range 0-5, healthy to severely disabled) [17], Time to 10 meter walk, Medical Research Council cum score on 12 muscles (range 0-60, most impaired to healthy) [20], inflammatory neuropathy causes and treatment (INCAT) sensory sum score (range 0-20, healthy to severe sensory loss) [21].

These were assessed at the baseline, 15 days, 2, 6 and 12 months after starting therapy. NCV was done before and after 15 days after therapy and 6 month after. Routine lab tests were done at study entry, 15 days after therapy, before, 2, 4 course of therapy and 1 month after $6^{\text {th }}$ course. BP measured after each infusion and intraocular tension was reassessed after 3 and 6 months. The primary outcome was the difference in the proportion of patients discontinuing treatment with IVIg /IV MP during 6 month of therapy because of side effects, intolerance, inefficacy (absence of improvement after 2 month or worsening after 15 days).

Several secondary outcomes were also assessed: the change of assessment scores after 15 days, 2 months and 6 month of therapy compared with baseline, the proportion of patients worsening by at least one point in the ONLS or MRS score during the 6 month after therapy discontinuation, the difference in the time to worsening after discontinuation, the difference in the proportion of patients without limitation on the ONLS (i.e. with score 0 or 1 , with one not in the lower limb and modified Rankin Score (i.e. with scores 0 or 1) at the end of 6 months, the proportion of patients unresponsive to the first therapy who improved after the alternative therapy, the proportion of patients experiencing adverse events during therapy and the change on nerve conductions before and after 6 month of therapy.

An independent data safety monitoring was not deemed to be necessary since both therapies are currently used in clinical practice and unexpected adverse events were deemed unlikely to occur.

Statistical analysis: A sample size of 40 patients was taken. All statistical analysis was done with significant 
set at the $5 \%$ level and using 2 sided tests or 2 sided 95 $\%$ CI.

The primary outcome was assessed by comparing treatment at each visit and longitudinally with univariate tests (Fisher's exact test and actuarial methods and multivariable tests (logistic regression and Cox-proportional hazard model.
A per person incidence rate of adverse events were reported for each group and its $95 \%$ CI was computed with the Poisson distribution method. The 2 groups were compared on the secondary binary outcome with the Fisher's exact test.

All other secondary outcomes were assessed with the Wilcoxon Mann-Whitney test and ANOVA. Data were analyzed with SPSS version.

\section{Results}

40 patients enrolled from December 2010 to September 2014. 20 patients treated with IV Methylprednisolon and 20 with IV Ig. Compared with patients in IVIg group, those in Methylprednisolon group tended to have a worse MRS score and ONLS score, to be older (Table-1). The sex ratio, mean disease duration, course of CIDP, MRC cum score was similar in the 2 groups (Table-1).

Table -1: Demographic and clinical characteristics.

\begin{tabular}{|c|c|c|}
\hline Features & IV MP (n-20) & IVIg $(\mathbf{n - 2 0})$ \\
\hline Men & 15 & 12 \\
\hline Women & 5 & 8 \\
\hline Age (years) & $66(39-60)$ & $54(19-70)$ \\
\hline CIDP & 14 & 13 \\
\hline Progressive & 6 & 7 \\
\hline Relapsing & $4(0-25)$ & $3(0-12)$ \\
\hline Disease Duration (yrs) & $4(2-9)$ & $3(2-5)$ \\
\hline ONLS & $3(2-5)$ & $2(1-4)$ \\
\hline MRS & & \\
\hline
\end{tabular}

8 of 20 patients $(40 \%)$ treated with IV Methylprednisolone completed the IV MP 6 months study period compared to 12 of 20 patients $(60 \%)$ with IVIg. The cumulative probability of treatment discontinuation was significantly higher with IV MP than with IV Ig at 15 days, 2 months and 6 months (Table-2).

Table 2: Cumulative Treatment Failure.

\begin{tabular}{|c|c|c|c|c|}
\hline Duration & $\begin{array}{c}\text { IV MP } \\
\mathbf{n - 2 0}\end{array}$ & $\begin{array}{c}\text { IVIg } \\
\mathbf{n - 2 0}\end{array}$ & $\begin{array}{c}\text { Relative risk } \\
(\mathbf{9 5 \%} \text { CI })\end{array}$ & P Value \\
\hline 15 days & 18 & 16 & $.75(.56-.99)$ & 0.0389 \\
\hline 2 months & 6 & 10 & $.65(.44-.97)$ & 0.0406 \\
\hline 6 months & $8(40 \%)$ & $12(60 \%)$ & $.54(.34-.87)$ & 0.0085 \\
\hline
\end{tabular}

When adjusted for sex, age, disease duration, co morbidities, mRS and ONLS scores at enrolment the difference between the 2 groups were significant $(95 \%$ CI 1.7-33.9; $\mathrm{p}=0.0070)$. The difference was also significant when we used the Cox model to analyse failure occurrence within 6 months. (Hazard ratio 3.7, 95\% CI 1.0-13.9, P=0.0414). 12 patients discontinued IV MP, among which 7 because of progressive worsening after treatment, 4 because of failure to improve, 1 because of adverse event (gastritis). Total 8 patients discontinued in IVIg group, 6 patients discontinued IVIg because of progressive worsening after therapy, 2 because of absence of improvement.

All patients worsening or not improving after either treatment were shifted to the alternative therapy. Both groups significantly improved at 6 month compared with baseline in MRS (Table-3). 
Table 3: Changes in secondary outcomes (intention-to-treat analysis).

\begin{tabular}{|c|c|c|c|}
\hline & IV MP (n-20) & IV Ig (n-20) & P value \\
\hline \multicolumn{4}{|l|}{ MRS } \\
\hline ENROLEMENT & $3(2-5)$ & $2(1-4)$ & --- \\
\hline 15 days & $2(1-5)$ & $2(0-4)$ & .1742 \\
\hline 2 months & $2(0-5)$ & $2(0-3)$ & .1413 \\
\hline 6 months & $2(0-5)$ & $2(0-3)$ & .0228 \\
\hline $\mathrm{P}$ value* & .0220 & .0006 & $.3542+$ \\
\hline \multicolumn{4}{|l|}{ ONLS } \\
\hline ENROLMENT & $4(2-9)$ & $3(2-5)$ & --- \\
\hline 15 days & $4(1-9)$ & $3(0-8)$ & .1506 \\
\hline 2 months & $4(0-9)$ & $3(0-5)$ & .0388 \\
\hline 6 months & $3(0-9)$ & $2(0-5)$ & .1322 \\
\hline $\mathrm{P}$ value* & .0582 & $<.0001$ & $.4030+$ \\
\hline \multicolumn{4}{|l|}{ MRC cum score } \\
\hline ENROLEMENT & $51.0(7.7)$ & $53.2(7.0)$ & \\
\hline 15 days & $52.1(7.9)$ & $54.8(7.9)$ & 0.1089 \\
\hline 2 months & $53.1(7.7)$ & $56.8(4.5)$ & 0.0896 \\
\hline 6 months & $52.8(8.7)$ & $57.9(3.2)$ & 0.929 \\
\hline$P$ value & $1.8(0.1250)$ & $4.7(.0078)$ & $.6148+$ \\
\hline \multicolumn{4}{|l|}{ Time 10 meters walk } \\
\hline ENROLEMENT & $16.0(8.9)$ & $13.8(4.9)$ & \\
\hline 15 days & $13.9(8.7)$ & $13.0(4.9)$ & 1.0 \\
\hline 2 months & 13.7(11.6) & $11.4(3.9)$ & .6131 \\
\hline 6 months & $15.5(12.2)$ & $10.6(4.2)$ & .2300 \\
\hline $\mathrm{P}$ value & $-0.5(.2051)$ & $-3.2(.0025)$ & $.0800+$ \\
\hline
\end{tabular}

Patients treated with IVIg also improved in ONLS score, mRS cum score, timed 10 meters walk. No significant difference in the degree of improvement between the two groups seen. The proportion of patients without limitation in the ONLS and mRS scores at the end of 6 month was similar in the IVIg group 8/20 and in the IV MP group 8/20 $(\mathrm{p}=.6852)$.

The analysis of the variations in the 2 most relevant motor nerves for the diagnosis of CIDP showed a marginal nonsignificant improvement in both the groups in distal and proximal amplitude of CMAPS in motor conduction velocities. The only significant difference was in the reduction in the distal latency in the IVIg group. 3 of 8 patients of IVIg group who did not improved showed improvement with methylprednisolone and 5/12 patients of IV MP group who did not improved showed improvement with IVIg. During 6 month after therapy discontinuation, none of the patients who had improved with IVMP worsened and required further therapy where as 8/20 patients (38.5\%) who had responded to IVIg worsened 1-5 months (median 4 months) after the last therapy, they all responded to resumed therapy. At the end of month 12 of study 10/20 patients (50\%) treated with MP and 12/20 (54\%) patients treated with IVIg improved (p-0.763)

A total of 34 adverse events were reported in 20 patients treated with IV MP including one with gastritis leading to discontinuation and 18 in 20 patients treated with IVIg group (Table-4). 
Table 4-Adverse events in the two groups.

\begin{tabular}{|c|c|c|}
\hline Parameters & IVMP & IVIg \\
\hline High BP & 3 & 3 \\
\hline Hyperglycemia & 2 & 1 \\
\hline Weight gain & 2 & 0 \\
\hline Epigastric pain & 2 & 1 \\
\hline Gastritis & 1 & 1 \\
\hline Vomiting & 0 & 1 \\
\hline Headache & 0 & 1 \\
\hline Peripheral edema & 2 & 0 \\
\hline Dyspnea & 1 & 1 \\
\hline Flu like syndrome & 0 & 3 \\
\hline Cough & 0 & 1 \\
\hline Depression & 1 & 1 \\
\hline Agitation & 1 & 0 \\
\hline Insomnia & 2 & 0 \\
\hline Lower limb pain & 1 & 0 \\
\hline Delirium & 1 & 0 \\
\hline Visual Hallucinations & 1 & 0 \\
\hline
\end{tabular}

The proportion of patients having at least one adverse event did not significantly differ between the IV MP group (10/20; $50 \%)$ and IVIg group (10/20 patients; $50 \%)$, p value is 0.1600 .

\section{Discussion}

Treatment of CIDP with IVIg for 6 months was less frequently discontinued because of intolerance, inefficacy or adverse events than was treatment with intravenous methylprednisolone. Assessment scores showed that responses were more favorable in the IVIg group as compared to methylprednisolone group.

Limitation of the study was the imbalance of some baseline characteristics in the two treatment groups. The small sample size prevented further safety and efficacy assessment in patient subgroups. Patients treated with intravenous methyl prednisolone tended to be older and have more functional impairments than did patients treated with IVIg.

However, our results could be applicable to treatment of patients in an active or stationary phase of the disease with significant disability, without contraindication to steroids or IVIg, and who have not failed to respond to one of the treatments. We used monthly pulse intravenous methylprednisolone, because this regimen allowed us to mask the treatment of patients in the hospital with the same type of intravenous regimen used for IVIg. Compared with intravenous methylprednisolone, oral prednisolone therapy would have been continued at home and would have required the preparation of a different oral placebo. In addition, to make the two regimens identical for the patient and the nurse, we gave intravenous methylprednisolone for 4 consecutive days in the same way as IVIg administration.

Corticosteroids are effective in patients with CIDP when prescribed orally [22] and the dose of $60 \mathrm{mg}$ per day of prednisolone is usually thought to correspond with a monthly dose of $1350 \mathrm{mg}$ intravenous methylprednisolone. The pulse dose of oral dexamethasone of $160 \mathrm{mg}$ per month was used, equivalent to $850 \mathrm{mg}$ intravenous methylprednisolone in the prednisolone treatment for chronic inflammatory demyelinating polyradiculoneuropathy (PREDICT) study [14]. The dose of intravenous methylprednisolone used in our study ( $0.5 \mathrm{~g}$ per day for 4 consecutive days) was in the range of doses used in other trials in patients with inflammatory neuropathies, including GuillainBarre syndrome (e.g., intravenous methyl prednisolone $0.5 \mathrm{~g}$ per day for 5 consecutive days in addition to IVI) [23] and with CIDP (intravenous methylprednisolone 1 $\mathrm{g}$ per day for 3-5 consecutive days followed by maintenance infusions of $1 \mathrm{~g}$ per week for a month and subsequent tapering doses for 1-2 years) [24]. A few reports on a small series of patients described a similar 
efficacy when steroids were prescribed in pulsed monthly doses or daily regimens [24-26] and a randomized trial [14] showed comparable efficacy of standard oral prednisolone and pulsed, high-dose, monthly oral dexamethasone over 6 months. In some of the studies, pulsed corticosteroids were associated with fewer adverse events than daily oral steroids [24-26]. However, the high dose of intravenous methylprednisolone used in our study might explain the non-significant higher rate of adverse events in the methylprednisolone group than in the IVIg group. IVIg and oral prednisolone had the same efficacy after 2 weeks of therapy in a short-term trial [10]. We did not find a significant difference in the degree of improvement between IVIg and intravenous methyl prednisolone even after 6 months of therapy, but more patients were able to continue therapy with IVIg than with methylprednisolone. However, the early shift of therapy by patients treated with methylprednisolone who deteriorated or did not improve after 2 months excluded patients who might have later improved as indicated by the PREDICT study, in which the median time to improvement in the pulsed dexamethasone group was 17 weeks [14]. Our study also showed that, when efficacious and tolerated, intravenous methyl prednisolone was associated with fewer relapses than IVIg after discontinuation of therapy. Similar long-term efficacy of corticosteroids was reported in six of ten patients treated with pulsed high-dose dexamethasone who sustained improvement for 6 months after therapy discontinuation [26] Additionally, the follow-up of the PREDICT study showed that the median time to relapse after therapy discontinuation ranged from 11.0 months for oral prednisolone to 17.5 months for pulsed dexamethasone [27] The longer efficacy of corticosteroid than that of IVIg after discontinuation could be relevant to the long-term treatment of CIDP.

Most patients with CIDP require long-term therapy, facing the inconveniences of repeated infusions and high costs related to IVIg or of side-effects often associated with the prolonged use of corticosteroids [28]. These inconveniences have led to the use of immunosuppressive agents in CIDP [29]. The efficacy of which has not been confirmed in randomized studies [19, 30-32]. Whether the high dose of corticosteroids used in our study delayed progression compared with IVIg or induced longer remission will be clarified by a follow-up study. The lower cost of intravenous methylprednisolone along with above described factors might favour the choice of this drug as initial treatment for patients with CIDP.
On the one hand, long-term use of IVIg was less frequently discontinued because of inefficacy, intolerance and adverse events than was treatment with intravenous methylprednisolone. On the other hand, methylprednisolone induced a longer-term remission than did IVIg. Whether the later difference might also affect the chronic course of the disease remains to be clarified.

\section{Conclusion}

We showed that treatment of CIDP with IVIg for 6 months was less frequently discontinued because of inefficacy, inefficacy or adverse events than was treatment with intravenous methylprednisolone.

Future studies are required to assess whether the longerterm efficacy of intravenous methylprednisolone compared with IVIg has an effect on the chronic course of CIDP.

Acknowledgement-The study was conducted in the hospital and no funds from any agency or committee was taken. The investigations and hospital stay charges were made concession.

\section{Abbreviations: \\ CIDP-Chronic inflammatory polyradiculoneuropathy, IVMP-Intravenous methylprednisolone, IVIg-Immuno- globulin MRC-Medical Research Council, ONLS- Overall neuropathy limitation scale, mRS- Modified Rankin scale. \\ Funding: Nil, Conflict of interest: None initiated. Permission from IRB: Yes}

\section{References}

1. Hahn AF, Hartung HP, Dyck PJ. Chronic inflammatory demyelinating polyradiculoneuropathy. In: Dyck PJ, Thomas PK, eds. Peripheral Neuropathy, 4th edn. Philadelphia: Elsevier; 2005.2221-53.

2. Vallat JM, Sommer C, Magy L. Chronic inflammatory demyelinating polyradiculoneuropathy: diagnostic and therapeutic challenges for a treatable condition. Lancet Neurol. 2010 Apr;9(4):402-12. doi: 10.1016/S1474-4422(10)70041-7.

3. Lunn MP, Manji H, Choudhary PP, Hughes RA, Thomas PK. Chronic inflammatory demyelinating polyradiculoneuropathy: a prevalence study in south east England. J Neurol Neurosurg Psychiatry. 1999 May;66(5):677-80. 
4. Kusumi M, Nakashima K, Nakayama H, Takahashi K. Epidemiology of inflammatory neurological and inflammatory neuromuscular diseases in Tottori Prefecture, Japan. Psychiatry Clin Neurosci. 1995 Jun; 49(3):169-74.

5. Laughlin RS, Dyck PJ, Melton LJ 3rd, Leibson C, Ransom J, Dyck PJ. Incidence and prevalence of CIDP and the association of diabetes mellitus. Neurology. 2009 Jul 7;73(1):39-45. doi: 10.1212/WNL. 0b013e 3181 aaea 47 .

6. Hughes RA, Allen D, Makowska A, Gregson NA. Pathogenesis of chronic inflammatory demyelinating polyradiculoneuropathy. J Peripher Nerv Syst. 2006 Mar;11(1):30-46.

7. Mehndiratta MM, Hughes RA, Agarwal P. Plasma exchange for chronic inflammatory demyelinating polyradiculoneuropathy. Cochrane Database Syst Rev. 2004;(3):CD003906.

8. Eftimov F, Winer JB, Vermeulen M, de Haan R, van Schaik IN. Intravenous immunoglobulin for chronic inflammatory demyelinating polyradiculoneuropathy. Cochrane Database Syst Rev 2009; 1: CD001797.

9. Mehndiratta MM, Hughes RAC. Corticosteroids for chronic inflammatory demyelinating polyradiculoneuropathy. Cochrane Database Syst Rev 2002; 1: CD002062.

10. Hughes R, Bensa S, Willison H, Van den Bergh P, Comi G, Illa I, Nobile-Orazio E, van Doorn P, Dalakas M, Bojar M, Swan A; Inflammatory Neuropathy Cause and Treatment (INCAT) Group. Randomized controlled trial of intravenous immunoglobulin versus oral prednisolone in chronic inflammatory demyelinating polyradiculoneuropathy. Ann Neurol. 2001 Aug;50 (2): 195-201.

11. Dyck PJ, Litchy WJ, Kratz KM, Suarez GA, Low PA, Pineda AA, Windebank AJ, Karnes JL, O'Brien PC. A plasma exchange versus immune globulin infusion trial in chronic inflammatory demyelinating polyradiculoneuropathy. Ann Neurol. 1994 Dec;36 (6): 838-45.

12. Hughes RA, Donofrio P, Bril V, Dalakas MC, Deng C, Hanna K et al. Intravenous immune globulin $(10 \%$ caprylate-chromatography purified) for the treatment of chronic inflammatory demyelinating polyradiculoneuropathy (ICE study): a randomized placebocontrolled trial. Lancet Neurol 2008; 7 : 136-44.
13. Merkies IS, Bril V, Dalakas MC, Deng C, Donofrio P, Hanna K, Hartung HP, Hughes RA, Latov N, van Doorn PA; ICE Study Group. Health-related quality-oflife improvements in CIDP with immune globulin IV 10\%: the ICE Study. Neurology. 2009 Apr 14;72(15):1337-44. doi: 10.1212/WNL. Ob013e 3181a0fd80.

14. van Schaik IN, Eftimov F, van Doorn PA, Brusse E, van den Berg LH, van der Pol WL, Faber CG, van Oostrom JC, Vogels OJ, Hadden RD, Kleine BU, van Norden AG, Verschuuren JJ, Dijkgraaf MG, Vermeulen M. Pulsed high-dose dexamethasone versus standard prednisolone treatment for chronic inflammatory demyelinating polyradiculoneuropathy (PREDICT study): a double-blind, randomised, controlled trial. Lancet Neurol. 2010 Mar;9(3):245-53. doi: 10.1016/ S1474-4422(10)70021-1. Epub 2010 Feb 2.

15. Joint Task Force of the EFNS and the PNS. European Federation of Neurological Societies/ Peripheral Nerve Society Guideline on management of chronic inflammatory demyelinating polyradiculoneuropathy: report of a joint task force of the European Federation of Neurological Societies and the Peripheral Nerve Society-First Revision. J Peripher Nerv Syst. 2010 Mar;15(1):1-9. doi: 10.1111/j.1529-8027. 2010. 00245.x.

16. Graham RC, Hughes RA. A modified peripheral neuropathy scale: the Overall Neuropathy Limitations Scale. J Neurol Neurosurg Psychiatry. 2006 Aug;77(8): 973-6. Epub 2006 Mar 30.

17. Bamford JM, Sandercock PA, Warlow CP, Slattery J. Interobserver agreement for the assessment of handicap in stroke patients. Stroke. 1989 Jun;20(6):828.

18. Joint Task Force of the EFNS and the PNS. European Federation of Neurological Societies/ Peripheral Nerve Society guideline on management of multifocal motor neuropathy. Report of a joint task force of the European Federation of Neurological Societies and the Peripheral Nerve Society--first revision. J Peripher Nerv Syst. 2010 Dec;15(4):295301. doi: 10.1111/j.1529-8027.2010.00290.x.

19. RMC Trial Group. Randomised controlled trial of methotrexate for chronic inflammatory demyelinating polyradiculoneuropathy(RMC trial): a pilot, multicentre study. Lancet Neurol. 2009 Feb;8(2):158-64. doi: 10.1016/S1474-4422(08)70299-0. Epub 2009 Jan 10. 
20. Kleyweg RP, van der Meché FG, Schmitz PI. Interobserver agreement in the assessment of muscle strength and functional abilities in Guillain-Barré syndrome. Muscle Nerve. 1991 Nov;14(11):1103-9.

21. Merkies IS, Schmitz PI, van der Meché FG, van Doorn PA. Psychometric evaluation of a new sensory scale in immune-mediated polyneuropathies. Inflammatory Neuropathy Cause and Treatment (INCAT) Group. Neurology. 2000 Feb 22;54(4):943-9.

22. Dyck PJ, O'Brien PC, Oviatt KF, Dinapoli RP, Daube JR, Bartleson JD, Mokri B, Swift T, Low PA, Windebank AJ. Prednisone improves chronic inflammatory demyelinating polyradiculoneuropathy more than no treatment. Ann Neurol. 1982 Feb; 11(2):136-41.

23. van Koningsveld R, Schmitz PI, Meché FG, Visser LH, Meulstee J, van Doorn PA; Dutch GBS study group. Effect of methylprednisolone when added to standard treatment with intravenous immunoglobulin for Guillain-Barré syndrome: randomised trial. Lancet. 2004 Jan 17;363(9404):192-6.

24. Lopate G, Pestronk A, Al-Lozi M. Treatment of chronic inflammatory demyelinating polyneuropathy with high-dose intermittent intravenous methylprednisolone. Arch Neurol. 2005 Feb;62(2):24954.

25. Muley SA, Kelkar P, Parry GJ. Treatment of chronic inflammatory demyelinating polyneuropathy with pulsed oral steroids. Arch Neurol. 2008 Nov; 65(11):1460-4. doi: 10.1001/archneur.65.11.1460.
26. Molenaar DS, van Doorn PA, Vermeulen M. Pulsed high dose dexamethasone treatment in chronic inflammatory demyelinating polyneuropathy: a pilot study. J Neurol Neurosurg Psychiatry. 1997 Apr;62 (4):388-90.

27. Eftimov F, Vermeulen M, van Doorn PA, Brusse E, van Schaik IN; PREDICT. Long-term remission of CIDP after pulsed dexamethasone or short-term prednisolone treatment. Neurology. 2012 Apr 3;78 (14):1079-84. doi: 10.1212/WNL. 0b013e31824 e8f84. Epub 2012 Mar 21.

28. Dukes MN. Meyler's side effects of drugs. New York: Elsevier, 1996: 1193-209.

29. Mahdi-Rogers $\mathbf{M}^{1}$, Swan $\mathrm{AV}$, van Doorn PA, Hughes RA. Immunomodulatory treatment other than corticosteroids, immunoglobulin and plasma exchange for chronic inflammatory demyelinating polyradiculoneuropathy. Cochrane Database Syst Rev. 2010 Nov 10;(11):CD003280. doi: 10.1002/14651858.CD 003280. pub3.

30. Dyck PJ, O'Brien P, Swanson C, Low P, Daube J. Combined azathioprine and prednisone in chronic inflammatory - demyelinating polyneuropathy. Neurology. 1985 Aug;35(8):1173-6.

31. Hadden RDM, Sharrack B, Bensa S. Randomized trial of interferon beta-1a in chronic inflammatory demyelinating polyradiculoneuropathy. Neurology 1999; 53: 57-61.

32. Hughes RAC, Gorson KC, Cros D, A Sandrock. Intramuscular interferon beta-1a in chronic inflammatory demyelinating polyradiculoneuropathy. Neurology 2010; 74: 651-57.

\section{How to cite this article?}

Kashyap PV, Bhat SJ. Intravenous methylprednisolone versus intravenous immunoglobulin in chronic inflammatory demyelinating polyradiculoneuropathy: a randomized trial. Int J Med Res Rev 2016;4 (7):1130-1137.doi: 10.17511/ijmrr.2016.107.11. 